\title{
ANNOTATION
}

\section{Ophthalmic Disabilities among the Clergy in Mediaeval Times}

The following abstract and notes are taken from the publications of the Cantilupe Society, which society was formed about twenty years ago with the object of transcribing and publishing the Registers of the Bishops of Hereford. They throw some light on ophthalmic disabilities in mediaeval times and may be of interest to our readers.

September 6, 1322. Adam ${ }^{1}$, to his well beloved in Christ, Robert, Vicar of Fownhope, greeting. The works of Charity and the importance of your conversation and other virtuous gifts with which God, in his infinite mercy, has blessed.you, demand that we should gratify you as much as we are able, the Lord being our helper. If you wish to resign the present vicarage which you hold; with our diocesan authority, by these presents, we grant indulgence that notwithstanding the defect which is very apparent in the pupil of one of your eyes, you may be admitted to any other vicarage in our diocese if it is canonically offered to you, and instituted in the same. In witness whereof, etc., Dated at Prestbury, VIth.. day of September, A.D. MCCCXXII.

In the Register of Thomas Spofford ${ }^{2}$, under date 26 August, 1429, John Delew receives a dispensation that he may be ordained in spite of a defect (macula) which he has in his right eye.

In the Register of Charles Bothe ${ }^{3}$, dated 29 March, 1521, occurs a dispensation to Walter Winnall to all the Holy orders in spite of a clouding (nebula) of the left eye.

Whether it was common form or not for a parson with any corporeal defect to have to obtain a dispensation from the Bishop of his diocese in order to take a post in the diocese, we do not know; or whether this occurred solely on the Welsh Marches. The Bishops of Hereford would appear to have had liberal ideas in ophthalmological matters.

In the case of the two latter parsons the defect is clearly stated, and was probably the result of a previous corneal ulcer of severe type. It is not easy to offer a solution in the first case, but we would suggest a coloboma of the iris as a possible condition.

2 Thomas Spofford, Bishop of Hereford, A.D. 1421-1448.

3 Charles Booth, Bishop of Hereford, A.D. 1516-1535. 